\title{
Brain potentials reflect violations of gender stereotypes
}

\author{
LEE OSTERHOUT, MICHAEL BERSICK, and JUDITH MCLAUGHLIN \\ University of Washington, Seattle, Washington
}

\begin{abstract}
Event-related brain potentials (ERPs) were recorded while 14 males and 14 females read sentences containing a reflexive pronoun that referred to a definitionally or stereotypically male or female antecedent noun. Pronouns that disagreed with the gender definition or gender stereotype of the antecedent elicited a large-amplitude positive wave. Violations of gender definitions elicited a larger positive wave than did violations of gender stereotypes. Furthermore, the positive wave elicited by stereotype violations persisted even when subjects judged these sentences to be acceptable. Finally, female subjects exhibited larger positivities than did male subjects, regardless of whether the gender mismatch involved a definitional or stereotypical antecedent. These results are taken to indicate that ERPs are sensitive to violations of gender-based occupational stereotypes and that the ERP response to stereotype violations is similar to the $\mathrm{P} 600$ effect elicited by a variety of syntactic anomalies.
\end{abstract}

Recent work has indicated that syntactic and pragmatic anomalies encountered during reading elicit distinct changes in the event-related brain potential (ERP). ERPs are scalp-recorded voltage changes in the electroencephalogram that are time-locked to the onset of a sensory, motor, or cognitive event (for a review, see Rugg \& Coles, 1995, or Hillyard \& Picton, 1987). ERPs consist of positive and negative voltage deflections (or "components") that are distributed over time. Some of these components are sensitive to language-related events. In a series of seminal experiments, Kutas and Hillyard (1980a, 1980b, 1980c) discovered that pragmatically implausible words (e.g., "I like my coffee with cream and dog") elicit an enhanced negative-going wave with a peak amplitude at about $400 \mathrm{msec}$ (the $N 400$ effect; see Kutas \& Van Petten, 1994). More recently, other researchers (Hagoort, Brown, \& Groothusen, 1993; Neville, Nicol, Barss, Forster, \& Garrett, 1991; Osterhout, 1990, in press; Osterhout \& Holcomb, 1992, 1993; Osterhout, Holcomb, \& Swinney, 1994; Osterhout, McKinnon, Bersick, \& Corey, 1996; Osterhout \& Mobley, 1995; Osterhout \& Nicol, 1996; for a review, see Osterhout, 1994) have reported that a disparate set of syntactic anomalies (including anomalies involving phrase structure, verb subcategorization, verb tense, and constituent movement) elicits a large positive wave

We thank Tony Greenwald, Laurie Rudman, Sean Draine, Rick McKinnon, Vicka Corey, Michael Masson, and two anonymous reviewers for helpful comments on previous versions of this paper: David Hessl and Michael Backstrom for carrying out the ratings pretest; Dawn Aiken and Linda Mobley for help with stimulus construction; and especially Marjorie Osterhout for lively discussions leading to this experiment. This research received financial support from Grant R29 DC01947 from the National Institute of Deafness and Other Communication Disorders, National Institutes of Health. Please address correspondence and reprint requests to L. Osterhout. Department of Psychology, Box 351525, University of Washington, Seattle, WA 98195 (e-mail: losterho@u.washington.edu). with an onset at about $500 \mathrm{msec}$ and a duration of several hundred milliseconds. This positive wave has been variously labeled the P600 effect (Osterhout \& Holcomb, 1992) and the syntactic positive shift (Hagoort et al., 1993). Importantly, the P600 effect is qualitatively distinct from the N400 effect.

Of particular relevance to the present study is evidence that violations of agreement between sentence constituents elicit a P600-like positivity (Hagoort et al., 1993; Osterhout, in press; Osterhout et al., 1996; Osterhout \& Mobley, 1995). In current grammars, agreement is incorporated within a theory of syntax (Haegeman, 1991). Number, gender, and other agreement features are represented as a feature bundle residing under an inflectional node within the sentence. These features are mechanically copied from the "controller" (e.g., nouns in subject position) to the "controllee" (e.g., tensed verbs and pronouns) in a purely formal manner. Consistent with this treatment, a variety of agreement violations, including violations of subject-verb number agreement (e.g., "Most cats likes to play outside"), reflexive pronoun-antecedent number agreement (e.g., "The hungry guests helped himself to the meal"), and reflexive pronoun-antecedent gender agreement (e.g., "The woman blamed himself for the accident"), elicit a large-amplitude positive wave that is quite similar to the P600 effect elicited by a variety of syntactic anomalies (Hagoort et al., 1993; Osterhout, in press; Osterhout \& Mobley, 1995; Osterhout et al., 1996).

The present study was primarily motivated by one finding reported by Osterhout and Mobley (1995) - namely, that reflexive pronouns disagreeing in gender with a definitionally male or female antecedent elicit a P600-like effect. In the research reported here, we examined the brain response to reflexive pronouns that refer to stereotypically male or female antecedent nouns. ${ }^{2}$ Consider a sentence containing a reflexive that is inconsistent with the presumed gender bias of a noun indicating a stereo- 
typed occupational role (e.g., "The doctor prepared herself for the operation"). Because the reflexives in such sentences would be perceived to be anomalous only if the occupational stereotypes exist, the presence of a "linguistic anomaly" effect (i.e., the N400 or P600) in the ERPs to these reflexives would indicate that subjects (and ERPs) are sensitive to stereotype violations. Furthermore, the qualitative nature of the anomaly effect might provide an initial basis for speculating about the mental representations and processes underlying the response to the stereotype violations. One possibility is that the perceived anomaly results from an evaluation of the pragmatic plausibility of a male playing a stereotypically female role or of a female playing a stereotypically male role. If so, stereotype violations might be expected to elicit a brain response similar to that elicited by pragmatically inappropriate words ( $\mathrm{N} 400$ ). Alternatively, the gender properties of stereotypically male or female nouns might be represented in much the way that the gender properties of definitionally male or female nouns are thought to be represented - as a grammatical feature associated with the word's lexical representation. Under this scenario, stereotype-violating reflexives might be perceived as violating the grammatical constraint requiring feature agreement between the reflexive and its antecedent, and might therefore elicit a brain response similar to that elicited by agreement violations and other syntactic anomalies (P600).

To summarize: the present study was designed to investigate two questions. First, is the ERP response to stereotype-violating reflexives distinct from the response to reflexives that are consistent with these stereotypes? Second, if an ERP response to stereotype violations is observed, does this response most closely resemble the response to pragmatically implausible words $(\mathrm{N} 400)$ or the response to syntactically anomalous words (P600)?

\section{METHOD}

\section{Subjects}

Twenty-eight right-handed, native-English-speaking undergraduates (14 males and 14 females) with normal or corrected-to-normal vision participated for course credit. Ages ranged from 19 to 35 years.

\section{Stimuli}

A set of 249 nouns specifying occupations (e.g., actress), states (c.g., bachelor), and titles (e.g., duke) was selected by the experimenters. Approximately half of these nouns were definitionally male or female (e.g., bachelor) and half were stereotypically male or female (e.g., doctor), as determined by the experimenters' judgment. Estimates of gender bias for these nouns were obtained in a ratings pretest. Forty adults (17 males and 23 females; 22 undergraduates, 14 full-time employees, and 4 nonstudent part-time employees) served as subjects in the ratings pretest. Subjects rated each noun on a 7-point Likert-type scale with the anchors of 1 (extremely male) and 7 (extremely female) and a midpoint of 4 (gender neutral). The mean ratings and standard deviations for nouns selected for use in the ERP study are shown in Table 1. Subject age, sex, and employment/student status did not have reliable effects on the ratings of these nouns.

The critical stimuli were 160 sentences containing a noun in subject position and a reflexive pronoun acting as object of either the main verb or a preposition. In all cases, the subject noun acted as antecedent to the reflexive. These antecedent nouns were either definitionally or stereotypically male or female. Eighty sentences contained a definitionally male or female subject noun indicating an occupation, state, or title. In 40 of these sentences, the reflexive and subject agreed in all respects, whereas in the other 40 sentences the reflexive and subject disagreed in gender. The remaining 80 sentences contained a subject noun indicating an occupation that was stereotypically male or female. The gender of the reflexive was consistent with the stereotype in 40 sentences and inconsistent in the remainder. (See Table 1 for example sentences.) Equal numbers of definitionally male or female or biased male or female nouns were used in each condition. The entire set of experimental sentences is provided in the Appendix.

In addition to these sentences, 80 filler sentences were also added, half of which contained linguistic anomalies that did not involve agreement. These stimuli were used to create two stimulus lists, so that each subject saw only one version of each sentence and 40 exemplars of matching and mismatching reflexives in the definitional and stereotypical conditions. Sentences were randomized prior to presentation.

\section{Procedure}

Each trial consisted of the following events: A fixation cross appeared for $500 \mathrm{msec}$, after which a sentence was presented in a word-by-word manner, with each word appearing on the center of the screen for $300 \mathrm{msec}$. A blank-screen interval of $350 \mathrm{msec} \mathrm{sep}-$ arated words. Sentence-ending words appeared with a period. A 1,450-msec blank-screen interval followed each sentence, after which a prompt appeared, asking subjects to decide whether the preceding sentence was "acceptable" or "unacceptable." Acceptable sentences were defined as those which were semantically coherent and grammatically well formed. Subjects responded by pressing one of two buttons, which were counterbalanced (left and right) across subjects. Subjects were tested in one session which lasted approximately $2 \mathrm{~h}$, during which they were seated in a comfortable chair located in an isolated room.

\section{Data Acquisition and Analysis}

Continuous EEG was recorded from 13 scalp sites, using tin electrodes attached to an elastic cap (Electrocap International). Electrode placement included International 10-20 system locations

Table 1

Examples of Sentence Types and Pretest Mean Ratings (and Standard Deviations) of Subject Noun Gender Properties on a 7 -point scale $(1=$ very male, $7=$ very female $)$

\begin{tabular}{llll} 
& & \multicolumn{2}{c}{ Ratings } \\
\cline { 4 - 5 } Sentence Type & & $M$ & $S D$ \\
\hline $\begin{array}{llll}\text { Definitional } \\
\text { Male }\end{array}$ & The man prepared himself/herself for the interview. & 1.36 & .26 \\
$\quad$ Female & The woman prepared herself/himself for the interview. & 6.83 & .20 \\
Stereotypical & & & \\
Male & The doctor prepared himself/herself for the operation. & 2.63 & .74 \\
Female & The nurse prepared herself/himself for the operation. & 5.43 & .63 \\
\hline
\end{tabular}


(Jasper, 1958) over homologous positions over the left and right occipital $(\mathrm{O} 1, \mathrm{O} 2)$ and frontal $(\mathrm{F} 7, \mathrm{~F} 8)$ regions and from frontal $(\mathrm{Fz})$, central $(\mathrm{Cz})$, and parietal $(\mathrm{Pz})$ midline locations. In addition, several nonstandard sites over posited language centers were used, including Wernicke's area and its right-hemisphere homologue (WL, WR: $30 \%$ of the interaural distance lateral to a point $13 \%$ of the nasioninion distance posterior to $\mathrm{Cz}$ ), posterior temporal (TL, TR: $33 \%$ of the interaural distance lateral to $\mathrm{Cz}$ ), and anterior temporal (ATL, ATR: one half the distance between F7/F8 and T3/T4). Vertical eye movements and blinks were monitored by means of two electrodes, one placed beneath the left eye and one placed to the right of the right eye. The 15 channels above were referenced to an electrode placed over the left mastoid bone and were amplified with a bandpass of 0.01 to $100 \mathrm{~Hz}$ ( $3 \mathrm{~dB}$ cutoff) by a Grass Model 12 amplifier system. Activity over the right mastoid was actively recorded on a 16 th channel to determine whether there were any effects of the experimental variables on the mastoid recordings. No such effects were observed.

Continuous analog-to-digital conversion of the EEG and stimulus trigger codes was performed by a Data Translation 2801-A board and a 486-based computer at a sampling frequency of $200 \mathrm{~Hz}$. Epochs comprised the $100 \mathrm{msec}$ preceding and $1,180 \mathrm{msec}$ following presentation of individual words in the sentences. Trials characterized by excessive eye movement or amplifier blocking were removed prior to averaging. ERPs were quantified as the mean voltage within a latency range following presentation of words of interest relative to a baseline of activity that comprised the $100 \mathrm{msec}$ prior to presentation of the words of interest. Analyses of variance (ANOVAs) were performed on mean amplitude within three time windows: $150-300,300-500$, and $500-800 \mathrm{msec}$. These windows were chosen because they roughly correspond to the latency ranges of the N1-P2 complex, N400 component, and P3/P600 positivities often reported in cognitive ERP studies. Data acquired at midline and lateral sites were treated separately to allow for quantitative analysis of hemispheric differences. On data acquired over midline sites, ANOVAs were performed with repeated measures on two levels of gender properties (definitional, stereotypical), two levels of agreement (agree, disagree), and three levels of electrode site. On data acquired over lateral sites, ANOVAs involved repeated measures on gender properties, agreement, two levels of hemisphere (left, right), and five levels of electrode site. Reliable interactions were followed whenever appropriate by simple effects analyses (see Keppel, 1982); the error term for these analyses was the withingroups mean square from the original omnibus ANOVA. To protect against Type I error due to violations of the assumption of equal variances of differences between conditions of within-subjects factors, the Greenhouse-Geisser (1959) correction was applied when evaluating effects with more than one degree of freedom. In such cases, the corrected $p$ value is reported. For analyses examining differences in scalp topography across conditions (i.e., interactions involving the hemisphere and electrode site factors) in the presence of a significant main effect, two sets of analyses were reported: analyses on raw data, and analyses on data normalized according to the procedure described by McCarthy and Wood (1985). This normalization procedure was used because in certain cases, spurious interactions can result if the experimental effects are of different overall amplitude. To minimize the number of reported analyses, analyses of normalized data will be reported only if the effect was deemed to be theoretically important. ${ }^{3}$

\section{RESULTS}

\section{Acceptability Judgments}

Subjects judged the four types of sentences containing reflexives to be acceptable on the following percentages of trials: definitional match versus mismatch, $83 \%$ and
$15 \%$; stereotypical match versus mismatch, $93 \%$ and $77 \%$. A three-way ANOVA with the between-subjects factor of subject gender and the within-subjects factors of agreement condition (match, mismatch) and antecedent type (definitional, stereotypical) revealed main effects of agreement condition $[F(1,18)=382, p<.0001]$ and antecedent type $[F(1,18), 330, p<.0001]$, as well as a reliable interaction between these factors $[F(1,18)=$ $310, p<.0001]$. Subject gender had no reliable effects. Planned comparisons, in the form of two-tailed $t$ tests, revealed reliable differences between the matching and mismatching sentences in both the definitional $[t(27)=$ $27.58, p<.001]$ and stereotypical $[t(27)=7.33, p<$ $.001]$ conditions.

\section{Event-Related Potentials}

\section{ERPs to Reflexive Pronouns}

ERPs (averaged over all subjects and items) to the reflexive pronouns in the definitional and stereotypical conditions are shown in Figure 1. (Approximately 11\% of the trials were rejected for eyeblinks and other artifacts. These trials were evenly distributed across the treatment conditions.) Difference waves, formed by subtracting the definitional and stereotypical match conditions from the respective mismatch conditions, are plotted in Figure 2. Mismatching reflexives in both the definitional and stereotypical conditions elicited a posteriorly distributed slow positive wave. This positivity had an onset at about $300 \mathrm{msec}$ in the definitional condition and $400 \mathrm{msec}$ in the stereotypical condition and was larger in amplitude in the definitional condition.

Statistical analyses confirmed these observations. No reliable differences between conditions were observed within the $150-$ to $300-\mathrm{msec}$ window. Between 300 and $500 \mathrm{msec}$, ERPs to mismatching reflexives were more positive going than those to matching reflexives, but only for the definitional condition. [Match, mismatch $\times$ definition, stereotype: midline, $F(1,26)=5.08, M S_{\mathrm{e}}=6.82$, $p<.05$; lateral, $F(1,26)=4.39, M S_{\mathrm{e}}=8.07, p<.05$. Simple effects analyses on midline data: definitional, $F(1,26)$ $=12.56, p<.01 ;$ stereotypical, $F(1,26)<1, p>.5$.] The largest-amplitude differences were observed between 500 and $800 \mathrm{msec}$. ERPs to mismatching reflexives were more positive going than those to matching reflexives [midline, $F(1,26)=33.48, M S_{\mathrm{e}}=17.04, p<.0001$; lateral, $\left.F(1,26)=25.81, M S_{\mathrm{e}}=14.82, p<.001\right]$, particularly over posterior regions [match, mismatch $\times$ electrode site: midline, $F(2,52)=17.95, M S_{\mathrm{e}}=1.57, p<.01$; lateral, $\left.F(4,104)=20.65, M S_{\mathrm{e}}=3.24, p<.0001\right]$. Furthermore, this effect was larger in amplitude in the definitional condition than in the stereotypical condition [definition, stereotype $\times$ match, mismatch: midline, $F(1,26)=14.39$, $M S_{\mathrm{e}}=6.93, p<.001 ;$ lateral, $F(1,26)=10.19, M S_{\mathrm{e}}=$ $12.41, p<.01$ ], particularly over posterior sites [definition, stereotype $\times$ match, mismatch $\times$ electrode site: $F(2,52)=7.00, M S_{\mathrm{e}}=0.81, p<.01 ;$ lateral, $F(4,104)=$ $\left.5.72, M S_{\mathrm{e}}=1.18, p<.01\right]$. Simple effects analyses (on midline data) computed separately for the definitional and 


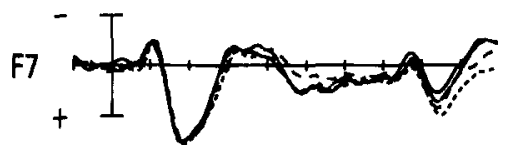

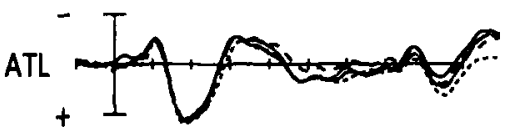

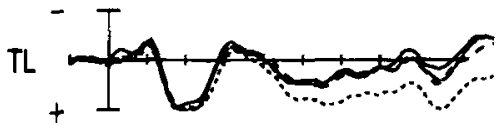

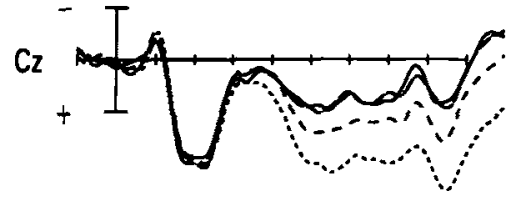
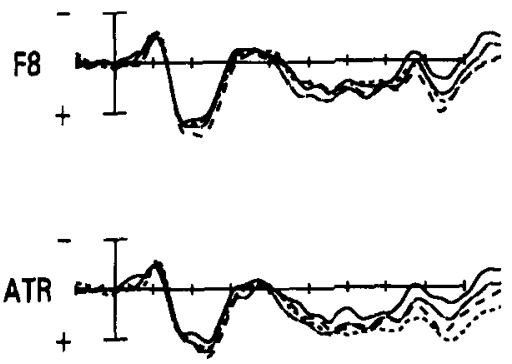

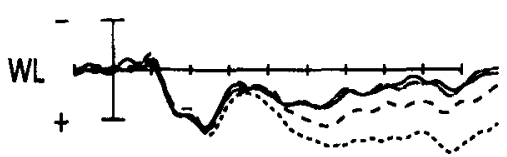

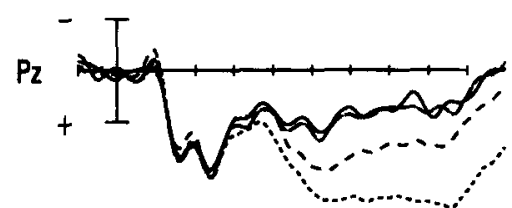

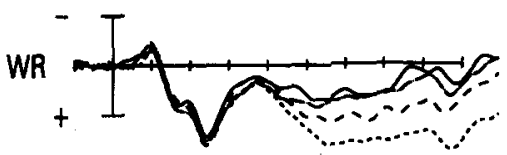

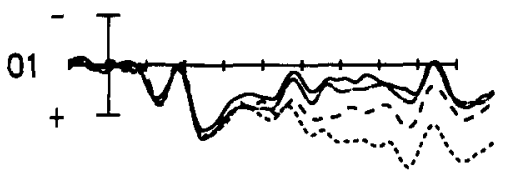
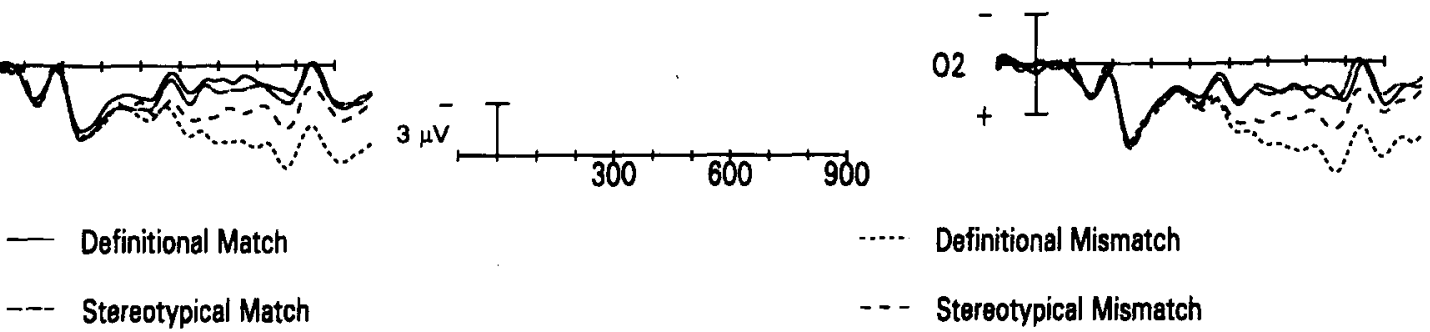

-.... Definitional Mismatch

- - Stereotypical Mismatch

Figure 1. Grand-average ERPs (averaged over all subjects and trials) elicited by reflexive pronouns that agreed or disagreed with the gender of definitionally or stereotypically male or female antecedent nouns. Word onset is indicated by the vertical calibration bar. Each hash mark represents 100 msec. Positive voltage is plotted down.

stereotypical conditions revealed that, for both conditions, ERPs to mismatching reflexives were reliably more positive going than those to matching reflexives [definitional condition, $F(1,26)=33.36, p<.0001$; stereotypical condition, $F(1,26)=5.67, p<.05]$, most notably at posterior sites [match, mismatch $\times$ electrode site: definitional condition, $F(2,52)=13.28, p<.01$; stereotypical condition, $F(2,52)=2.93, p<.1]$. Finally, simple effects analyses comparing ERPs elicited in the matching definitional and stereotypical conditions revealed no reliable differences $(p>.6)$.

One important question is whether the positive waves elicited in the definitional and stereotypical conditions were generated by identical neural systems. An approximate answer to this question can be obtained by comparing the scalp topographies of these positive waves. It is generally agreed that ERPs with distinct scalp topographies are necessarily generated by distinct brain systems (Johnson, 1993). We compared the topographies of the difference waves formed by subtracting the definitional and stereotypical match conditions from the respective mismatch conditions (see Figure 2). The difference waves most directly reflect the brain activity elicited in response to the anomaly. We performed ANOVAs on mean amplitude within the critical 500- to 800-msec window. No reliable differences in topography were found at midline sites [definitional, stereotypical $\times$ electrode site, $F(2,52)=$ $2.19, p>.1]$. Analyses involving data collected over lateral sites revealed no hemispheric differences [definitional, stereotypical $\times$ hemisphere, $F(1,26)<1, p>.9$; definitional, stereotypical $\times$ hemisphere $\times$ electrode site, $F(4,104)<1, p>9$.9. A reliable interaction between the definitional, stereotypical factor and electrode site was found, but this effect was unreliable after normalization of the data [raw data, $F(4,104)=3.04, p<.05$; normalized data, $F(4,104)=1.13, p>.3]$.

Response-contingent averages. One explanation for the smaller effect in the stereotypical condition is that the positive shift was elicited on only the $23 \%$ of the trials on which subjects judged stereotype-violating sentences to be unacceptable. To test this possibility, we formed response-contingent averages over only the trials on which subjects indicated that the sentence was acceptable (Figure 3). ERPs to reflexives that mismatched the gender bias 

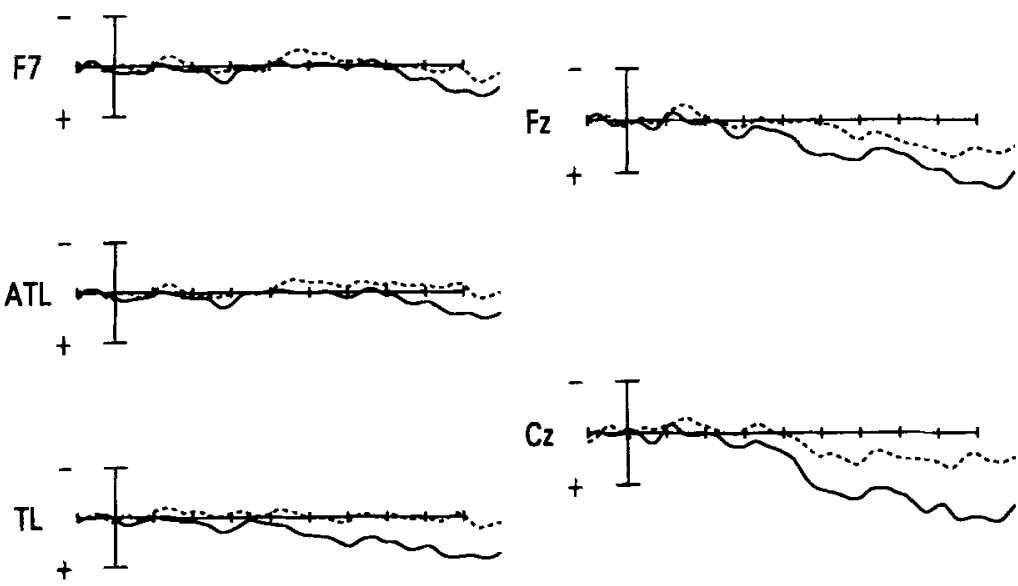

F8
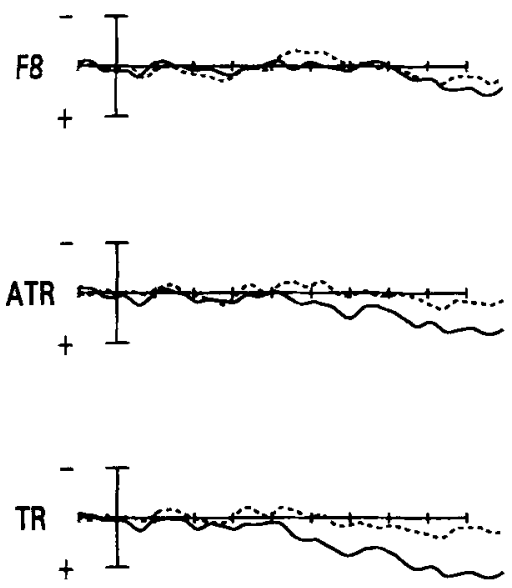

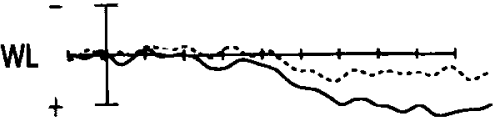

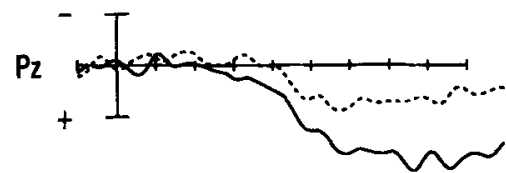
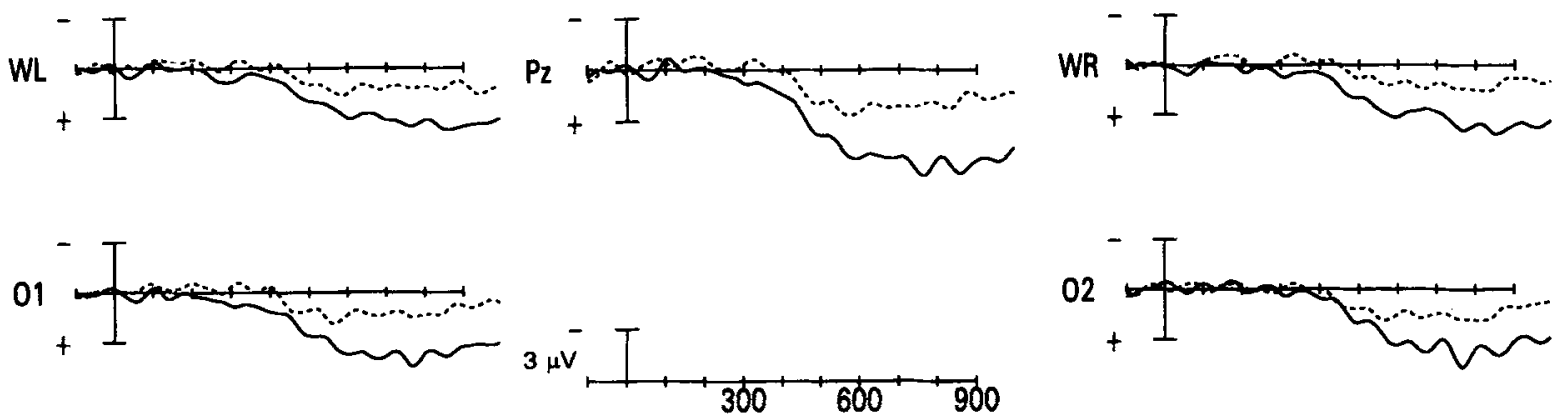

Definitional

Stereotypical

Figure 2. Difference waves formed by subtracting ERPs to reflexives that agreed with the gender of definitionally or stereotypically male or female antecedents from those that disagreed.

of their antecedent nouns were more positive going than those elicited by matching reflexives, particularly over posterior sites. [Main effect for match, mismatch: midline, $F(1,26)=4.69, M S_{\mathrm{e}}=10.73, p<.04$; match, mismatch $\times$ electrode site: lateral, $F(4,104)=8.87, M S_{\mathrm{e}}=$ $1.50, p<.05$.] Importantly, this effect was similar in magnitude to that observed when all trials were included.

Effects of subject gender. Figures 4 and 5 plot difference waves formed by subtracting ERPs to reflexives that matched the definitional or stereotypical gender of nouns from reflexives that mismatched, formed separately for female and male subjects. ${ }^{4}$ For both the definitional and stereotypical conditions, the positive shift to mismatching reflexives was much greater in amplitude for female subjects than for male subjects [subject gender $\times$ match, mismatch: midline, $F(1,26)=4.39, M S_{\mathrm{e}}=17.04, p<$ .05 ; lateral, $\left.F(1,26)=8.39, M S_{\mathrm{e}}=3.24, p<.01\right]$. Simple effects analyses revealed that, for female subjects, ERPs to mismatching reflexives were reliably more posjtive going than those to matching reflexives in both the definitional $[F(1,13)=25.62, p<.001]$ and stereotypical $[F(1,13)=7.95, p<.02]$ conditions. For male subjects, ERPs to mismatching reflexives were reliably more positive going than controls in the definitional condition
$[F(1,13)=9.89, p<.01]$, but not in the stereotypical condition $(p>.1)$.

Effects of antecedent gender. Effects of the gender of the antecedent noun would take the form of reliable interactions involving the factors of antecedent gender and reflexive antecedent type (matching or mismatching). However, no such interactions were observed $(p>.3$ in all analyses).

\section{ERPs to Sentence-Ending Words}

Prior work has indicated that ERPs to the final words in sentences containing a linguistic anomaly are more negative going than are ERPs to the same words in nonanomalous sentences, particularly within the window associated with the N400 component (i.e., between 300 and $500 \mathrm{msec}$; Hagoort et al., 1993; Osterhout \& Holcomb, 1992; Osterhout \& Mobley, 1995). ERPs to the sentencefinal words in the definitional and stereotypical conditions are plotted in Figures 6 and 7, respectively. Consistent with prior work, ERPs to the final words in sentences containing an outright agreement violation were more negative going than were those to controls ${ }^{5}$ [midline: $300-500 \mathrm{msec}$, $F(1,26)=45.98, M S_{\mathrm{e}}=10.08, p<.0001 ; 500-800$ msec, $\left.F(1,26)=21.42, M S_{\mathrm{e}}=19.13, p<.001\right]$. By con- 
<smiles>C=C1CN1CCOCCN1CCCC1</smiles><smiles>CC(C)(C)CC1CCC2(CC1)CCC2C(C)(C)C</smiles>

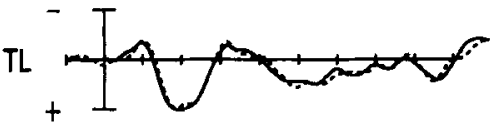

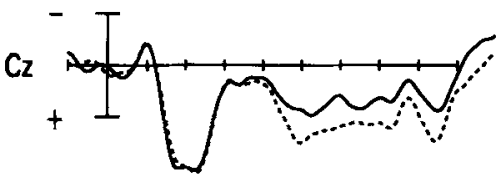

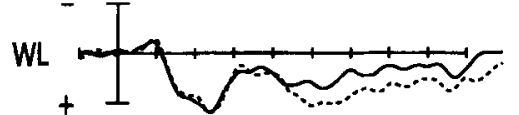

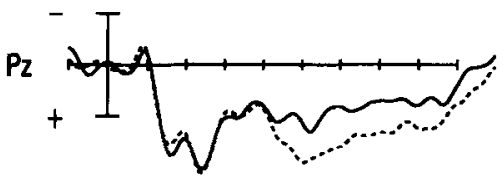

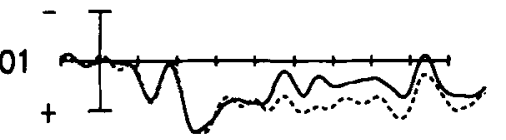

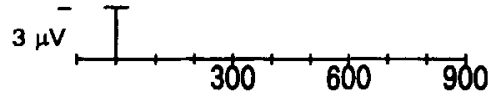

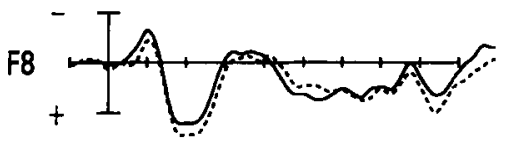

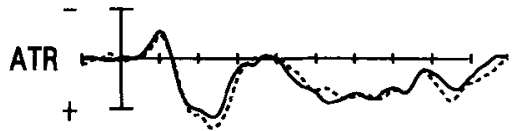

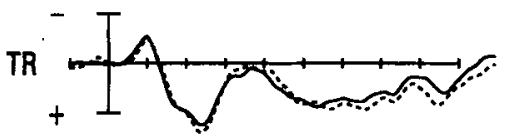

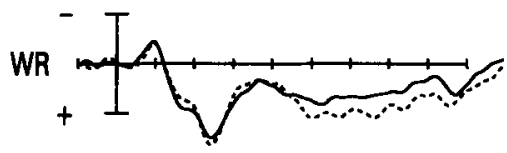

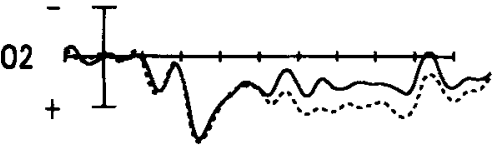

Stereotypical Mismatch

Figure 3. Response-contingent ERPs elicited by reflexive pronouns that agreed or disagreed with the gender bias of antecedent nouns, averaged over only those trials on which subjects judged the sentence to be acceptable.

trast, differences in ERPs to final words in the stereotype-violating and control sentences were much smaller in amplitude and were statistically reliable only in the 500 - to $800-\mathrm{msec}$ window $[300-500 \mathrm{msec}, F(1,26)=$ $2.28, p>.1 ; 500-800 \mathrm{msec}, F(1,26)=8.25, M S_{\mathrm{e}}=8.42$, $p<.01]$. Within both windows, differences between matching and mismatching sentences were reliably larger in the definitional than in the stereotypical condition [300$500 \mathrm{msec}, F(1,26)=14.32, M S_{\mathrm{e}}=9.11, p<.001 ; 500-$ $\left.800 \mathrm{msec}, F(1,26)=6.64, M S_{\mathrm{e}}=10.67, p<.02\right]$.

\section{DISCUSSION}

Several important observations have been reported here. First, violations of gender-based occupational stereotypes elicited a measurable ERP response. Second, this response was similar to the $\mathrm{P} 600$ effect elicited by agreement violations and other types of syntactic anomalies (cf. Osterhout, 1994), but it was quite distinct from the N400 effect elicited by pragmatic anomalies. Third, the positive shift persisted even when subjects judged the sentences containing a stereotype violation to be acceptable. Fourth, regardless of whether the mismatch involved a definitionally or stereotypically male or female ante- cedent, the response to agreement mismatches was much larger in female subjects than in male subjects.

These results seem to indicate that ERPs are sensitive to violations of at least one type of gender stereotype. Furthermore, assuming that cognitively distinct processes are mediated by neurally distinct brain systems, whereas the converse is true of cognitively similar processes, stereotype violations elicited a processing response similar to that elicited by grammatical violations but distinct from that elicited by pragmatic anomalies. Finally, it appears that ERPs can reveal a sensitivity to gender stereotypes even when certain types of explicit judgments do not.

Less clear, at present, is the set of cognitive processes underlying the positive shift and the relationship between these processes and subjects' personally held stereotypic beliefs. Perhaps the prevailing view within social psychology is that stereotypes are probabilistic generalizations about a social category or group (Brigham, 1971; McCauley et al., 1980). Interestingly, the amplitude of a well-known ERP component, the P300 complex of positivities, is inversely related to the subjective probability of the eliciting event (Donchin, 1981; Duncan-Johnson \& Donchin, 1977; Sutton \& Ruchkin, 1984). Hence, one reasonable hypothesis is that the the positive shift ob- 

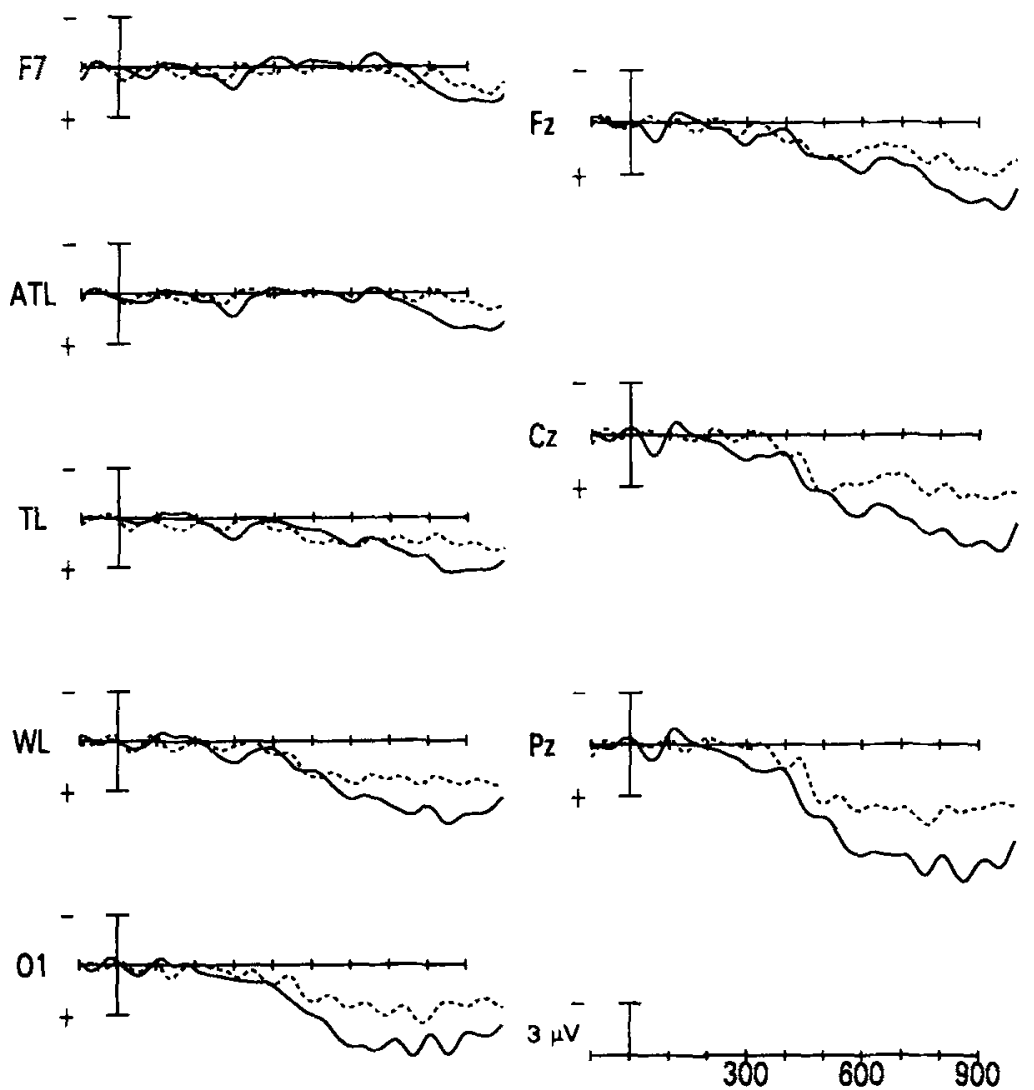

Definitional (Female)
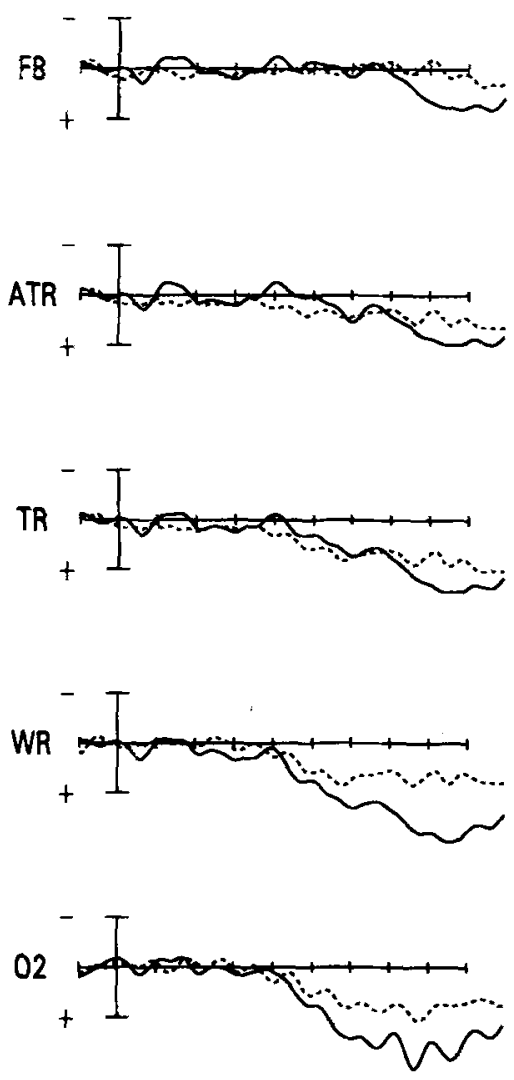

Definitional (Male)

Figure 4. Difference waves formed by subtracting ERPs to reflexives that agreed with the gender of definitionally male or female antecedents from those that disagreed, averaged separately over 14 male and 14 female subjects.

served here and "P600" effects observed elsewhere might be members of the P300 family. Correspondingly, the amplitude variation across the nonanomalous, stereotypeviolating, and definition-violating conditions might reflect the subjective probability of encountering a male or female in the various occupations, states, and titles.

However, three observations argue against a P300 account. First, in the present study, the amplitude of the positive shift did not perfectly covary with probability. For example, even though a male doctor is obviously less probable than a male bachelor, ERPs to reflexives that agreed with the gender of a "stereotypical" antecedent did not differ from those to reflexives that agreed with a "definitional" antecedent. This was true even though subjects in the materials pretest judged "stereotypical" nouns such as doctor to be less typically male or female than "definitional" nouns such as bachelor. Second, recent work in our laboratory has indicated that the P600 elicited by agreement violations is distinct from the $\mathrm{P} 300$ complex elicited by unexpected, task-relevant anomalies that do not involve the violation of a grammatical rule. These two responses seem to be at least partially independent and have distinct morphologies, time courses, scalp distributions, and differential sensitivities to changes in task and probability (Osterhout et al., 1996). In particular, Osterhout et al. (1996) reported that the positive shift to agreement anomalies was insensitive to manipulations of probability (but see Coulson, King, \& Kutas, 1995; Gunter, Vos, \& Mulder, 1995). It should be noted that the positive shift observed in the present study was similar in its morphology, time course, and distribution to the P600 reported by Osterhout et al. (1996) and others. Third, the P300 interpretation must somehow account for the fact that pragmatically anomalous words typically do not elicit a robust P300/P600-like effect, even when they are both improbable and task relevant (Neville et al., 1991; Osterhout, 1990, in press; Osterhout \& Mobley, 1995; Osterhout \& Nicol, 1996). Thus, it seems unlikely that the positive shift observed here is a manifestation of the domain-general response to any type of (linguistic or nonlinguistic) unexpected event, or that it primarily reflects subjective probability.

Another possibility is that the positive shift (and the P600 effect in general) is more specifically a response to grammatical anomalies encountered during language processing (cf. Osterhout et al., 1996). It is particularly noteworthy that both the "stereotype-violating" and the "definition-violating" reflexives elicited a positive shift 


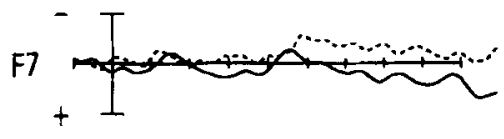

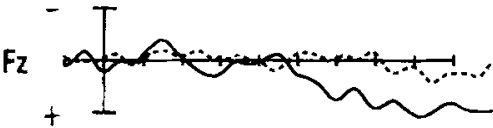

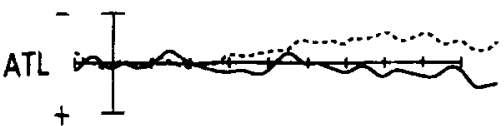<smiles>CC=CC=CN=CC=CC(C)(C)C</smiles>

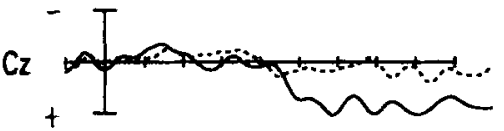
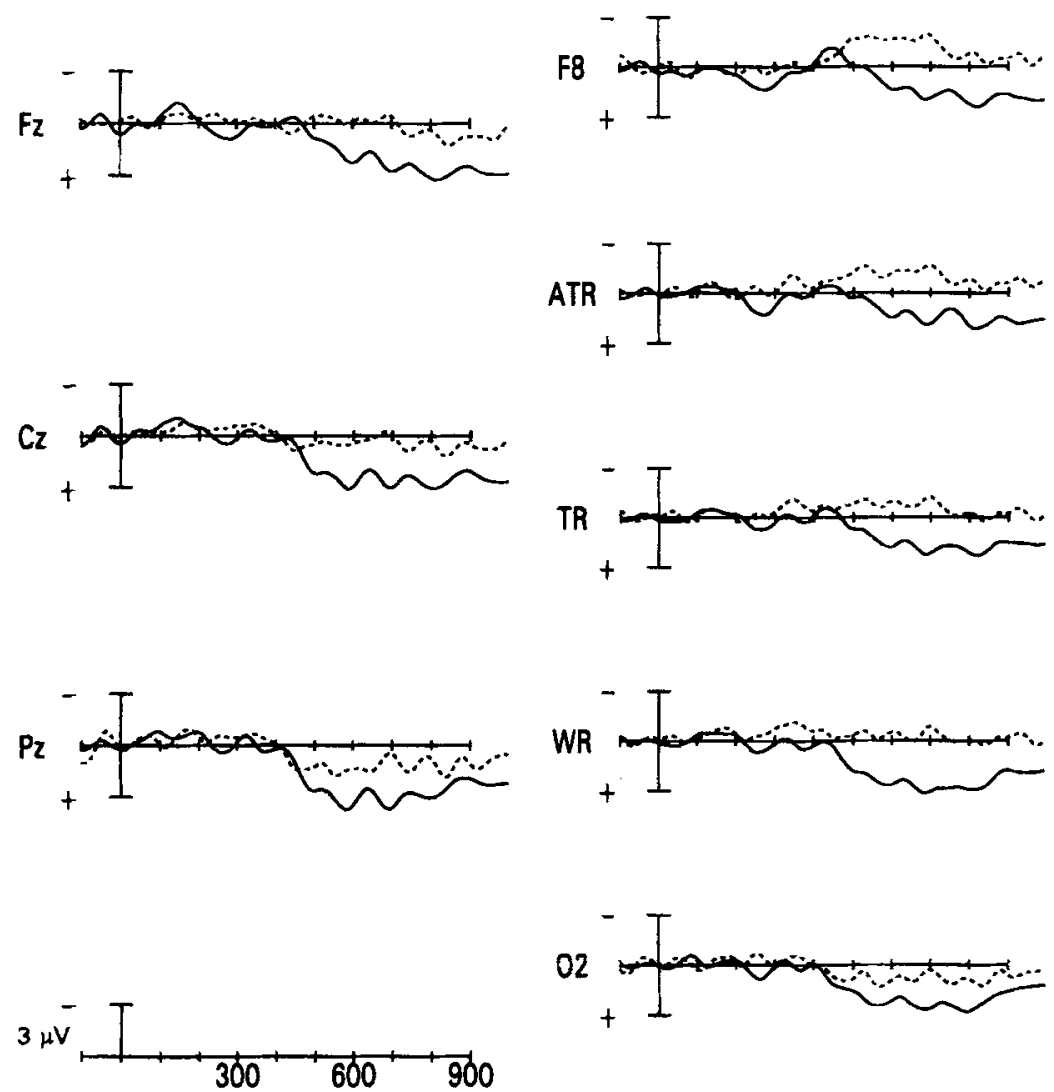

\section{Stereotypical (Male)}

Figure 5. Difference waves formed by subtracting ERPs to reflexives that agreed with the gender of stereotypically male or female antecedents from those that disagreed, averaged separately over 14 male and 14 female subjects.

that was similar to previously reported P600 effects but quite distinct from the $\mathrm{N} 400$ effect elicited by pragmatic anomalies. This result might indicate that the lexical representations of definitionally and stereotypically male or female nouns participate in the grammatical rules requiring agreement. ${ }^{6}$ One problem with this account is that, within linguistic theory, grammatical features are thought to be binary and content free. Thus, if we assume that the lexical representations of definitionally and stereotypically male or female nouns contain a feature marked [ + male] or [+female], a mismatch in features should be equally anomalous regardless of whether the feature belongs to a stereotypically or a definitionally male or female noun.

Nonetheless, we did observe amplitude variation across the stereotypical and definitional conditions. Definitional violations elicited a larger-amplitude response than did stereotypical violations. ${ }^{7}$ Two explanations for this amplitude variation are not inconsistent with a grammatical feature account. One explanation is that there was more variability in the gender feature representations for "stereotypical" nouns than for "definitional" nouns. If so, fewer subjects on fewer trials would have perceived the stereotype-violating reflexives to be anomalous, relative to the definition-violating reflexives. This would result in a larger-amplitude positivity in the definitional case than in the stereotypical case when one averages over subjects and trials, even if the two anomaly types elicited equal-amplitude effects on individual trials. This hypothesis predicts greater variance in the stereotypeviolating condition than in the definition-violating con-
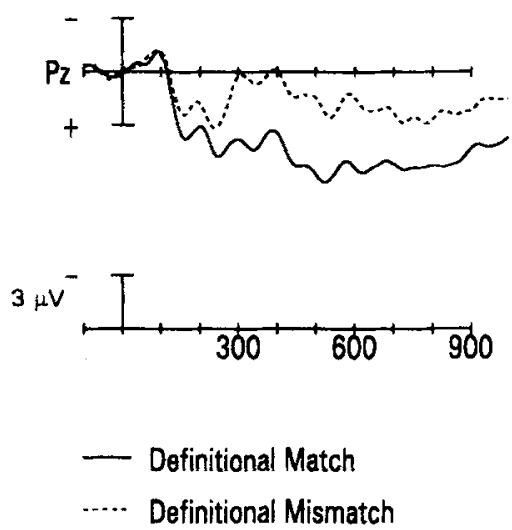

Figure 6. ERPs (recorded over $\mathrm{Pz}$ ) to sentence-final words in sentences containing a reflexive pronoun that agreed or disagreed with the gender of a definitionally male or female antecedent noun. 

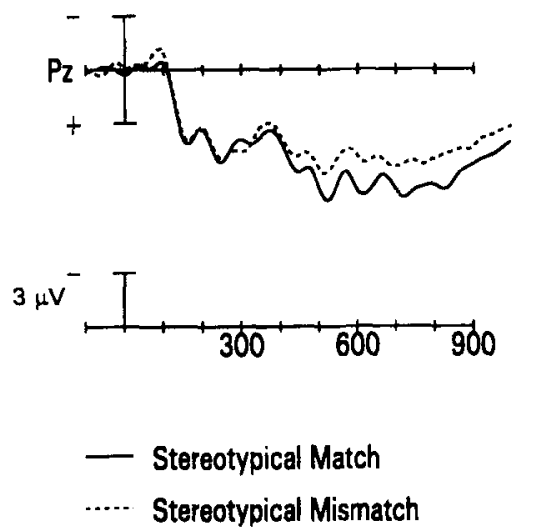

Figure 7. ERPs (recorded over $\mathrm{Pz}$ ) to sentence-final words in sentences containing a reflexive pronoun that agreed or disagreed with the gender bias of a stereotypically male or female antecedent noun.

dition. However, inspection of between-subjects variance indicated that the variance was actually greater in the definition-violating condition (standard errors: definitionviolating condition, $0.62 \mu \mathrm{V}$; stereotype-violating condition, $0.56 \mu \mathrm{V}){ }^{8}$

A second (and more interesting) explanation for the P600 amplitude variation is suggested by evidence that P600 amplitude reflects difficulty in recovering from, rather than detection of, a syntactic anomaly (Friederici, 1995; Osterhout et al., 1994). Evidence consistent with this notion has been reported by Osterhout et al. (1994), who examined the use of verb subcategorization information during on-line sentence processing. Subcategorization information specifies the set of permissible constituents licensed by the verb. For example, transitive verbs (e.g., force) require a direct object, whereas intransitive verbs (e.g., hope) do not allow a direct object. Other verbs can appear with or without a direct object but "prefer" to be used either transitively or intransitively (e.g., charge and believe, respectively; see Connine, Ferreira, Jones, Clifton, \& Frazier, 1984). Several studies have indicated that the sentence parser initially attempts to use the "preferred" subcategorization frame for a given verb, with backtracking and reanalysis occurring when the less preferred subcategorization frame turns out to be appropriate (Holmes, Stowe, \& Cupples, 1989). Consistent with this view, Osterhout et al. (1994) reported that outright violations of verb subcategorization and violations of subcategorization preferences both elicited a P600-like response. However, P600 amplitude was much larger following outright violations than following violations of preferences. Osterhout et al. (1994) speculated that P600 amplitude is a function of the ease with which a coherent grammatical analysis of the sentence can be derived following the detection of an anomaly. Outright violations of verb subcategorization cannot be recovered from, whereas violations of subcategorization preferences simply force the "less-preferred" interpretation. Similarly, violations of gender definitions result in an unavoidable ungrammaticality, whereas violations of stereotypes force the less preferred gender assignment onto the antecedent noun. One speculation is that readers initially assigned the "preferred" (i.e., stereotypical) gender feature to stereotypically male or female nouns and were subsequently forced to assign the less preferred gender feature upon encountering a reflexive pronoun that was inconsistent with the stereotype. ERPs elicited by sentence-ending words are also consistent with this interpretation. Prior work has shown that final words in anomalous sentences elicit an enhanced N400-like effect (Osterhout \& Holcomb, 1992; Osterhout \& Mobley, 1995). In the present study, final words in sentences containing a definition-violating reflexive elicited an enhanced $\mathrm{N} 400$ like effect, whereas final words in sentences containing a stereotype violation did not. This finding suggests that an acceptable interpretation had been derived for the stereotype-violating sentences but not for the definitionviolating sentences, prior to encountering the sentencefinal word.

A more serious challenge to the "grammatical feature mismatch" interpretation is the observation of subject gender differences-the finding that the positive shift to stereotype violations (and violations of definitions) was larger in amplitude for female subjects than for male subjects. One explanation for this is provided by prior work indicating that females (on the average) are more grammatically competent than males (Rosenberg \& SuttonSmith, 1969; but see Fairweather, 1976). If so, females might be better than males at detecting agreement violations. This possibility seems unlikely in the present case, owing to the fact that males and females did not reliably differ in their sentence acceptability judgments. Nonetheless, we tested this hypothesis by forming separate ERP averages for 15 male and 15 female subjects who participated in an experiment reported elsewhere (Osterhout et al., 1996). Subjects read sentences containing a subject-verb number agreement violation (e.g., "The women believes ...") and well-formed controls. Agreement-violating verbs elicited positive shifts of similar amplitude regardless of the subject's gender (males, mean amplitude $=4.11 \mu \mathrm{V}$; females, mean amplitude $=$ $4.23 \mu \mathrm{V} ; p>$.9). Thus, it seems unlikely that the present findings are due to the fact that females are better at detecting agreement violations, or that the positive shift elicited by agreement violations is, in general, larger in amplitude for females than for males.

The subject gender effects might indicate, then, that the amplitude of the positive shift is not entirely determined by attempts to "patch up" the grammar of the sentence. An alternative possibility is that the amplitude of the positive shift reflects the "strength" of stereotypic beliefs and, correspondingly, that females hold stronger gender-related stereotypes than do males. However, recent work involving both explicit and implicit measures of stereotypes tends to support the opposite conclusion (Banaji \& Greenwald, 1995; Jessell \& Beymer, 1992) or has found no sex-based differences in the strength of gender-based stereotypes (Swim, Aikin, Hall, \& Hunter, 1995). Another hypothesis is that females respond more 
strongly than males to violations of social expectations about "appropriate" gender roles. This explanation is consistent with the observation that females responded more strongly than males to both definition-violating and stereotype-violating reflexives. Interestingly, Rudman (1996) reports that women, but not men, rated atypical self-promoting women to be less socially attractive and less hireable than (more typical) self-deprecating women. Clearly, however, more work is needed to determine the significance of the gender differences observed here and the implications of these differences for hypotheses about the cognitive events underlying the positive shift.

Our claim is that the gender stereotype violations elicited a P600 effect by virtue of the fact that gender information is encoded within the grammar. In English, the grammatical distinction between male and female gender corresponds almost perfectly to the semantic distinction between male and female sex. Anomalies involving social categories that are not marked in the grammar (e.g., race) should not elicit the P600 effect but might elicit the N400 effect associated with semantic/pragmatic aspects of language.

In summary, despite the uncertainties concerning the cognitive events underlying the P600 effect, the present study demonstrates that ERPs are sensitive to violations of gender-related social stereotypes. Gender-role stereotypes have been shown to exert powerful influences on behavior. For example, gender stereotypes influence mothers' perceptions of their children's abilities and children's self-perceptions (Eccles, Jacobs, \& Harold, 1990; Jacobs, 1992; Jacobs \& Eccles, 1992), and gender-related occupational stereotypes play a role in job choice, hiring, promotion, and compensation (Cleveland \& Landy, 1983; Heilman, Martell, \& Simon, 1988). However, research on stereotypes and their effects is beset by a problem of measurement (Dawes \& Smith, 1985). Although most researchers rely on introspective self-reports that require subjects to express their beliefs in terms of a categorical or numerical rating, self-reports do not invariably reflect attitudes and beliefs, particularly when the expression of the belief is perceived to be socially inappropriate $(\mathrm{Ca}$ cioppo, Crites, Bernston, \& Coles, 1993; Dawes \& Smith, 1985). Consequently, researchers have developed ingenious and sensitive indirect measures of stereotypes that do not rely on self-reports (see Banaji, Hardin, \& Rothman, 1993; Greenwald \& Banaji, 1995). The present findings allow one to hope that ERPs might eventually prove to be particularly advantageous tools for studying stereotypes: Perhaps uniquely among the available tools, ERPs might provide a relatively direct measure of stereotypic beliefs that does not rely on subjects' self-reports.

\section{REFERENCES}

Banaji, M. R., \& Greenwald, A. G. (1995). Implicit gender stereotyping in judgments of fame. Journal of Personality \& Social Psychologv. 68, 181-198.

Banaj, M. R., \& Hardin, C. D. ( 1996). Automatic stereotyping. Psvchological Science, 7, 136-141.
Banaji, M. R., Hardin, C., \& Rothman, A. J. (1993). Implicit stereotyping in person judgment. Journal of Personality \& Social Psychology, 65, 272-281.

Brigham, J. C. (1971). Ethnic stereotypes. Psychological Bulletin, 76, 15-38.

Cacioppo, J. T., Crites, S. L., Bernston, G. G., \& Coles, M. G. H. (1993). If attitudes affect how stimuli are processed, should they not affect the event-related brain potential? Psychological Science, $\mathbf{4}$, 108-112

Clark, H. H. (1973). The language-as-fixed-effect fallacy: A critique of language statistics in psychological research. Journal of Verbal Learning \& Verbal Behavior, 12, 335-359.

Cleveland, J. N., \& Landy, F. J. (1983). The effects of person and job stereotypes on two personnel decisions. Journal of Applied Psychology, 68, 609-619.

Connine, C., Ferreira, F., Jones, C., Clifton, C., \& Frazier, L. (1984). Verb frame preferences: Descriptive norms. Journal of Psycholinguistic Research, 13, 307-319.

Coulson, S., King, J., \& Kutas, M. (1995, March). The late show: The syntactic positive shift meets the late positive component. Poster presented at the Eighth Annual CUNY Conference on Human Sentence Processing.

DAwES, R. M., \& SMiTh, T. L. (1985). Attitude and opinion measurement. In G. Lindzey \& E. Aronson (Eds.), Handbook of social psychology: Vol. 1: Theory and method (pp. 509-566). New York: Random House.

Donchin, E. (1981). Surprise! ... Surprise? Psychophysiology, 18, 493-513.

Duncan-Johnson, C. C., \& Donchin, E. (1977). On quantifying surprise: The variation in event-related potentials with subjective probability. Psychophysiology, 14, 456-467.

Eccles, J. S., JaCOBS, J. E., \& HARold, R. (1990). Gender-role stereotypes, expectancy effects, and parents' role in the socialization of gender differences in self-perceptions and skill acquisition. Journal of Social Issues, 46, 182-201.

Falrweather, H. (1976). Sex differences in cognition. Cognition, 4, 231-280.

Friederici, A. D. (1995). The time course of syntactic activation during language processing: A model based on neuropsychological and neurophysiological data. Brain \& Language, 50, 259-281.

Greenhouse, S., \& Geisser, S. (1959). On methods in the analysis of profile data. Psychometrika, 24, 95-112.

Greenwald, A. G., \& BanaJi, M. R. (1995). Implicit social cognition: Attitudes, self-esteem, and stereotypes. Psychological Review, 102, 4-27.

Gunter, T. C., Vos, S. H., \& Mulder, G. (1995, March). Syntactic violations and ERPs: P600 or P3b? Poster presented at the Eighth Annual CUNY Conference on Human Sentence Processing.

HAEGEMAN, L. (1991). Introduction to government and binding theory. Oxford, U.K.: Blackwell.

Hagoort, P., Brown, C., \& Groothusen, J. (1993). The syntactic positive shift as an ERP measure of syntactic processing. Language \& Cognitive Processes, 8, 337-364.

Heilman, M. E., Martell, R. F., \& Simon, M. C. (1988). The vagaries of sex bias: Conditions regulating the underevaluation, equivocation, and overvaluation of female job applicants. Organizational Behavior \& Human Decision Processes, 41, 98-110.

Hillyard, S. A., \& Picton, T. W. (1987). Electrophysiology of cognition. In F. Plum (Ed.), Handbook of physiology: Section I. Neurophysiology (pp. 519-584). New York: New York Physiological Society.

Holmes, V., Stowe, L., \& Cupples, L. (1989). Lexical expectations in parsing complement-verb sentences. Journal of Memory \& Language, 28, 668-689.

JACOBS, J. E. (1992). The influence of gender stereotypes on parent and child math attitudes. Journal of Educational Psychology, 83, 518-527.

JACOBS, J. E., \& ECCLES, J. S. (1992). The impact of mothers' genderrole stereotypic beliefs on mothers' and children's ability perceptions. Journal of Personality \& Social Psychology, 63, 932-944.

JASPER, H. H. (1958). Report to the committee on methods of clinical 
examination in electroencephalography: Appendix. The ten-twenty system of the International Foundation. Electroencephalography \& Clinical Neurophysiology, 10, 371-375.

Jessel.L, J. C., \& BeYmer, L. (1992). The effects of job title vs. job description on occupational sex typing. Sex Roles, 27, 73-83.

JOHNSON, R., JR. (1993). On the neural generators of the P300 component of the event-related brain potential. Psychophysiology, 30, 90-97.

JUDD, C. M., \& PARK, B. (1993). Definition and assessment of accuracy in social stereotypes. Psychological Review, 100, 109-128.

KEPPEL, G. (1982). Design and analysis: A researcher's handbook. Englewood Cliffs, NJ: Prentice-Hall

KuTAS, M., \& Hillyard, S. A. (1980a). Event-related brain potentials to semantically inappropriate and surprisingly large words. Biological Psychology, 11, 99-116.

KuTAS, M., \& Hillyard, S. A. (1980b). Reading between the lines: Event-related brain potentials during natural sentence processing. Brain \& Language, 11, 354-373.

KUTAS, M., \& Hillyard, S. A. (1980c). Reading senseless sentences: Brain potentials reflect semantic incongruity. Science, 207, 203-205

Kutas, M., \& VAN Petten, C. K. (1994). Psycholinguistics electrified: Event-related brain potential investigations. In M. A. Gernsbacher Handbook of psycholinguistics (pp. 83-143). San Diego: Academic Press.

McCarthy, G., \& Wood, C. C. (1985). Scalp distributions of eventrelated potentials: An ambiguity associated with analysis of variance models. Electroencephalography \& Clinical Neurophysiology, 62, 203-208.

McCauley, C., Stitt, C. L., \& Segal, M. (1980). Stereotyping: From prejudice to prediction. Psychological Bulletin, 87, 195-208.

Münte, T. F., Heinze, H., \& Mangun, G. R. (1993). Dissociation of brain activity related to syntactic and semantic aspects of language. Journal of Cognitive Neuroscience, 5, 335-344.

Neville, H. J., Nicol, J. L., Barss, A., Forster, K. I., \& Garrett, M. F. (1991). Syntactically based sentence processing classes: Evidence from event-related brain potentials. Journal of Cognitive Neuroscience, 3, 151-165.

OSTERHOUT, L. (1990). Event-related brain potentials elicited during sentence comprehension. Unpublished doctoral dissertation, Tufts University.

OSTERHOUT, L. (1994). Event-related brain potentials as tools for comprehending language comprehension. In C. Clifton, Jr., L. Frazier, \& K. Rayner (Eds.), Perspectives on sentence processing (pp. 15-44) Hillsdale, NJ: Erlbaum.

OSTERHOUT, L. (in press). On the brain response to syntactic anomalies: Manipulations of word position and word class reveal individual differences. Brain \& Language.

OSTerhout, L., \& Holcomb, P. J. (1992). Event-related brain potentials elicited by syntactic anomaly. Journal of Memory \& Language, 31, 785-806.

Osterhout, L., \& Holcomb, P. J. (1993). Event-related potentials and syntactic anomaly: Evidence of anomaly detection during the perception of continuous speech. Language \& Cognitive Processes, 8 , 413-438.

Osterhout, L., Holcomb, P. J., \& Swinney, D. A. (1994). Brain potentials elicited by garden-path sentences: Evidence of the application of verb information during parsing. Journal of Experimental Psychology: Learning, Memory, \& Cognition, 20, 786-803

Osterhout, L., McKinnon, R., Bersick, M., \& Corey, V. (1996). On the language-specificity of the brain response to syntactic anomalies: Is the syntactic positive shift a member of the P300 family? Journal of Cognitive Neuroscience, 8, 507-526.

OSteRhout, L., \& Mobley, L. A. (1995). Event-related brain potentials elicited by failure to agree. Journal of Memory \& Language, 34, 739-773.

Osterhout, L., \& Nicol, J. (1996). On the distinctiveness, independence, and temporal course of the brain responses to syntactic and pragmatic anomalies. Manuscript submitted for publication.

RosenberG, B. G., \& SUTton-SMITH, B. (1969). Sibling age spacing effects upon cognition. Developmental Psychology, 1, 661-668.
Rösler, F, Friederici, A., Pütz, P., \& Hahne, A. (1993). Event-related brain potentials while encountering semantic and syntactic constraint violations. Journal of Cognitive Neuroscience, 5, 345-362.

RUDMAN, L. A. (1996). Self-promotion as a risk factor for women: The costs and benefits of counterstereotypical impression management. Manuscript in preparation.

RugG, M. D., \& Coles, M. G. H. (1995). Electrophysiology of mind: Event-related brain potentials and cognition. Oxford: Oxford University Press.

SutTon, S., \& Ruchkin, D. S. (1984). The late positive complex: Advances and new problems. In R. Karrer, J. Cohen, \& P. Tueting (Eds.), Brain and information: Event-related potentials (Annals of the New York Academy of Sciences, Vol. 425, pp. 1-23). New York: New York Academy of Sciences.

Swim, J. K., Aikin, K. J., Hall, W. S., \& Hunter, B. A. (1995). Sexism and racism: Old-fashioned and modern prejudice. Journal of Personality \& Social Psychology, 68, 199-214.

\section{NOTES}

1. Exceptions exist in the literature to the generalization that pragmatic anomalies elicit a monophasic negative-going wave (N400) whereas syntactic anomalies elicit a monophasic positive-going wave (P600). For example, in some reports syntactic anomalies have elicited a negativity over left anterior regions of the cortex in addition to eliciting a late positivity (Münte, Heinze, \& Mangun, 1993; Neville et al., 1991; Osterhout \& Holcomb, 1992; Rösler, Friederici, Pütz, \& Hahne, 1993). However, the claim that (at least under the conditions of the current study) the ERP responses to syntactic and pragmatic anomalies are dominated by the $\mathrm{P} 600$ and $\mathrm{N} 400$ effects, respectively, is supported by a substantial literature (see Osterhout, 1994, in press)

2 . Following recent theoretical work within social psychology, we assume that social stereotypes are probabilistic generalizations or predictions about the attributes of a social category or group (Brigham, 1971 Judd \& Park, 1993; McCauley, Stitt, \& Segal, 1980). These probabilistic generalizations might, but might not, accurately reflect the state of affairs in the real world.

3. A standard procedure within psycholinguistics for generalizing across items is to perform analyses treating items as a random variable (see Clark, 1973). However, for a number of reasons, items analyses are rarely performed on ERP data and were not performed in the present study. (For an extensive discussion of this issue, see Osterhout, 1994.) One reason for this is related to the signal-to-noise issue inherent in the signal-averaging procedure used to derive the ERP. In the present study, such analyses would involve averages over 14 or 28 wave forms (reflecting the number of subjects in the study), a number insufficient to obtain a desirable signal-to-noise ratio.

4. Difference waves were used in order to isolate the effects of the match, mismatch manipulation.

5. The term negative going is used to describe deviations from the "baseline" wave form elicited by the nonviolating sentences. Thus, ERPs elicited by sentence-ending words in the agreement-violating sentences were more negative going than those to the same words in the nonviolating sentences, even though both wave forms are positive in voltage.

6. Presumably, most people can distinguish between nouns that are definitionally male or female and nouns that are stereotypically male or female; thus, the gender information about these nouns is probably not represented identically, even if these representations contain gender features that participate in grammatical rules

7. It is interesting that in a recent behavioral priming study, Banaji and Hardin (1996) found that definitionally male or female occupations produced stronger priming effects than did stereotypically male or female occupations. Although the relationship between the priming effects and $\mathrm{P} 600$ amplitude is unknown, both sets of results are consistent with the notion that gender definitions and gender stereotypes have quantitatively (but perhaps not qualitatively) different processing effects.

8. Because of limitations imposed by the software and other concems (cf. Osterhout, 1994), within-subjects variability was not assessed. 


\section{APPENDIX \\ Experimental Stimuli Presented During the Experiment}

\section{Definitionally Female}

The foreign nanny taught herself/himself to speak English.

The lonely governess lost herself/himself in a good book.

The nervous actress prepared herself/himself to face the crowd.

The infamous princess looked at herself/himself in the mirror.

The old baroness covered herself/himself with jewels.

The grateful niece asked herself/himself how she could repay her aunt.

The capable girl scout built herself/himself a fire.

The wealthy queen built herself/himself a castle.

The tired milkmaid took it upon herself/himself to clean up.

The hungry waitress ordered herself/himself a burger.

The doubtful housewife sold herself/himself on the idea.

The pompous chairwoman patted herself/himself on the back.

The novice cowgirl surprised herself/himself with success.

The daring sister flew herself/himself to Paris.

The expectant mother bought herself/himself a suitcase.

The homeless widow built herself/himself a shelter.

The experienced midwife established herself/himself in the community.

The head policewoman assigned herself/himself to the job.

The athletic girl taught herself/himself how to shoot baskets.

The successful woman congratulated herself/himself on her promotion.

The aspiring showgirl taught herself/himself the part.

The famous ballerina prepared herself/himself for the performance.

The neglected wife bought herself/himself an anniversary present.

The gracious hostess introduced herself/himself to the guests

The industrious saleswoman congratulated herself/himself for earning a bonus.

The old lady gathered flowers for herself/himself every morning.

The rowdy maid calmed herself/himself with a glass of wine.

The jealous girlfriend told herself/himself not to worry.

The unhappy duchess killed herself/himself after the scandal.

The airsick stewardess poured herself/himself a glass of water.

The youthful grandmother planted herself/himself a garden.

The busy housewife threw herself/himself into the housework.

The shunned heiress cried herself/himself to sleep.

The calm bride prepared herself/himself for the wedding.

The eccentric spinster enjoyed herself/himself on the trip.

The busy landlady worked herself/himself into a frenzy.

The high priestess anointed herself/himself with oil.

The devout nun mumbled to herself/himself in church.

The industrious daughter put herself/himself through school.

The shy choirgirl forced herself/himself to sing the part.

\section{Definitionally Male}

The kindly uncle enjoyed himself/herself at Christmas.

The lonely bachelor cooked himself/herself dinner.

A young father needs to prepare himself/herself for raising children.

The overbearing patriarch found himself/herself alone.

The dutiful boy scout quizzed himself/herself for the test.

The devout priest crossed himself/herself at the alter.

The loyal butler prepared himself/herself for a controversy.

The wicked stepfather put himself/herself in charge.

The vain prince looked at himself/herself in the mirror.
The insecure king gave himself/herself a treasure.

The stubborn nephew found himself/herself written out of the will.

The lovestruck boy kissed himself/herself on the arm for practice.

The elderly gentleman fixed himself/herself up for the dance.

The old man got himself/herself out of bed.

The overbearing patriarch found himself/herself alone.

The desperate boyfriend told himself/herself to forgive the girl

The disoriented policeman lost himself/herself in the crowd.

The anxious cowboy prepared himself/herself for the rodeo.

The brave fireman pulled himself/herself from the flames.

The insecure son thought himself/herself unloved.

The ambitious count pictured himself/herself as king.

The talented landlord made himself/herself a fortune.

The tardy milkman found himself/herself out of a job.

The harassed congressman fixed himself/herself a drink.

The young husband found himself/herself without a job.

The heavyweight boxer hurt himself/herself before the match.

The confused brother wrote himself/herself a note.

The nervous groom checked himself/herself in the mirror.

The lonely grandfather made himself/herself a cup of tea.

The overweight deacon refused himself/herself the doughnut.

The grateful grandson bought himself/herself new clothes.

The greedy duke bought himself/herself a new limousine.

A salesman should enjoy himself/herself with customers.

The meeting chairman took himself/herself too seriously.

The busy waiter covered himself/herself with soup.

The pope enjoyed himself/herself in Colorado.

The enterprising businessman made himself/herself a fortune.

The bellboy hid himself/herself in the linen closet.

The tired mailman bought himself/herself a latte.

The telephone repairman let himself/herself into the house.

\section{Stereotypically Female}

The advice columnist found herself/himself the center of controversy.

Our aerobics instructor gave herself/himself a break.

The popular babysitter found herself/himself overcommitted on Fridays.

The beautician put herself/himself through school.

The beauty consultant never let herself/himself get carried away.

The caregiver fixed dinner for herself/himself and the children.

The enthusiastic cheerleader gave herself/himself a sore throat.

The childcare worker fixed herself/himself a cup of tea.

The skilled cosmetician found herself/himself a job.

The daycare manager prepared herself/himself to talk to the parents.

My dental hygienist enjoys herself/himself when she works.

The elementary school teacher hid herself/himself in the closet.

The feminist made herself/himself heard at the meeting.

The flight attendant pushed herself/himself off the rescue slide

The distracted florist cut herself/himself with the rose thorn.

The fortune teller lost herself/himself in thought.

The excited groupie snuck herself/himself backstage.

The ambitious gymnast pushed herself/himself to exhaustion.

The exotic gypsy cooked herself/himself a meal.

The weary hairdresser lit herself/himself a cigarette.

The housekeeper poured herself/himself a cup of coffee.

My interior decorator prides herself/himself on her work.

The young librarian enjoyed herself/himself at the party.

The magician's assistant prepared herself/himself for the stunt.

The talkative manicurist made herself/himself laugh.

The model saw a picture of herself/himself in the catalogue. 
The adventurous nurse put herself/himself on the list of volunteers.

The pro-choice advocate saw herself/himself on television.

Our friendly receptionist found herself/himself the center of attention.

The romance novelist cried herself/himself to sleep.

The secretary bought herself/himself a plane ticket.

The single parent bought herself/himself some flowers.

The soap opera fan lost herself/himself in the crowd.

The socialite surrounded herself/himself with friends.

The stenographer pushed herself/himself to get the job done.

The stripper made time for herself/himself after the show.

The switchboard operator talked to herself/himself during the blackout.

The synchronized swimmer forced herself/himself to learn the routine.

The tarot card reader made herself/himself a cup of tea.

The teenybopper worked herself/himself into a frenzy.

\section{Stereotypically Male}

The enraged ballplayer calmed himself/herself after the devastating loss.

The busy bartender ran himself/herself ragged.

The careless butcher cut himself/herself with a knife.

The hungry chef cooked dinner for himself/herself after work.

The clumsy clown tripped over himself/herself during the performance.

The busy dean always gave himself/herself time for a coffee break.

The dentist tried to make himself/herself popular with his patients.

The new diplomat drove himself/herself around the capitol.

The driver of the wrecked car pulled himself/herself through the window.

The famous drummer pictured himself/herself as a singer.

The electrician shocked himself/herself while he worked.

The picky executive did the work himself/herself during the meeting.

The daring explorer found himself/herself in uncharted territory.
The Norwegian farmer prided himself/herself on his crops.

The brave firefighter pulled himself/herself from the flames.

The treacherous general placed himself/herself on the throne.

The guitar player threw himself/herself into the crowd.

The successful hunter cleaned himself/herself after walking through the woods.

A successful inventor allows himself/herself to make mistakes.

The cautious jailer armed himself/herself with a gun.

The janitor fixed himself/herself a snack.

The revered leader revealed himself/herself to be a fraud

The brawny logger helped himself/herself to the hearty breakfast.

A good magician knows how to free himself/herself from a safe.

The respected mayor honored himself/herself with a party.

The greasy mechanic considered himself/herself to be very handsome.

A talented movie director can make himself/herself famous.

The convicted murderer killed himself/herself after the verdict was announced.

The newly elected official found himself/herself the center of controversy.

The experienced pilot prepared himself/herself for the emergency landing.

The young police officer trained himself/herself to stay calm.

The old rancher sang himself/herself to sleep.

The forest ranger readied himself/herself for the storm.

The seasick sailor threw himself/herself onto the bunk.

The careless scientist hurt himself/herself with the dangerous chemical.

The resourceful scout baked himself/herself a cake.

The popular senator promised himself/herself a vacation.

The dirty soldier cleaned himself/herself at the lake.

The weary trucker allowed himself/herself a one-hour nap.

The disciplined weight lifter trained himself/herself to get up early.

(Manuscript received June 19, 1996; revision accepted for publication December 9, 1996.) 